\title{
El grupo Estrujenbank y su proyecto en el Madrid de finales de los años 80 y principios de los 90
}

\author{
Carmen GonzÁlez García \\ Universidad Complutense de Madrid \\ Departamento de Historia del Arte III (Contemporáneo) \\ carmen.glezg@gmail.com
}

Recibido: 09-04-2012

Aceptado: 24-10-2012

\section{RESUMEN}

El artículo analiza la presencia del grupo Estrujenbank en la historia del arte español y su recorrido en el Madrid de la época. De esta forma trata de recuperar un legado que tiene un especial interés al mostrar la vitalidad que había en España y más concretamente en Madrid a finales de los años ochenta y principios de los noventa.

Palabras clave: Arte contemporáneo español, siglo XX, colectivos artísticos, salas independientes, performance.

\section{The Estrujenbank Group and its Project by the End of the 80's and the Beginning of the 90's in Madrid}

\begin{abstract}
This article analizes the relevance of the collective art group Estrujenbank in the history of Spanish art, and its path in contemporary Madrid. It therefore aims to recover a cultural heritage of special importance, since it shows the vitality that characterized Spain, and particularly Madrid, by the end of the 1980s and the beginning of the 1990s.
\end{abstract}

Key words: Spanish Contemporary Art, XX Century, Artistic Groups, Independent Galleries, Performance.

Sumario: 1. Madrid. 2. Nueva York. 3. Formación Estrujenbank. 4. Actividades del colectivo. 5. Producción Estrujenbank. 6. Disolución del grupo. 7. Conclusiones. 
Estrujenbank fue un colectivo formado por los artistas plásticos Patricia Gadea (Madrid 1960- Palencia 2006), Mariano Lozano (Cuenca, 1942) y Juan Ugalde (Bilbao, 1948) y por el poeta Dionisio Cañas (Tomelloso, 1949). El grupo comenzó a gestarse en Madrid en el año 1985, trasladándose dos de sus componentes posteriormente a Nueva York, en el año 1986, donde la idea de formar un grupo fue madurando, para convertirse posteriormente en un proyecto materializado entre los años 1989 y 1993 en la capital española.

A pesar de su corta vida, el colectivo artísticamente fue muy fructífero: llevaron a cabo varias exposiciones, crearon un espacio independiente donde organizaban muestras de otros colectivos que no tenían cabida en el circuito artístico madrileño de la época, publicaron libros y revistas y también realizaron performances.

\section{Madrid}

A la hora de acercarnos al contexto histórico artístico de la década de los ochenta, período en el cual surge el colectivo, es necesario mencionar previamente lo que ocurrió en España en la década anterior, puesto que lo sucedido en los años ochenta fue en buena medida una consecuencia directa de lo que comenzó a gestarse en los años setenta.

Como bien es sabido nuestro país estuvo bajo el gobierno de una dictadura casi cuarenta años, por este motivo, debido tanto a una fuerte represión y desinterés por el mundo de la cultura, como a un escape importante de intelectuales al extranjero por su no afinidad con el régimen, el país vivió de espaldas a lo que ocurría fuera de sus fronteras durante la mayoría del tiempo, sufriendo la vida cultural las consecuencias de los acontecimientos políticos, sobre todo durante el período de la autarquía.

A finales de los años sesenta y durante la década de los setenta (ya en época de la Transición) se produjo una gran expansión artística que culminó su proceso en la década de los ochenta. Fueron estos unos años políticamente marcados por la consolidación de las libertades recuperadas tras el fin de la dictadura y económicamente acompañados por una pujanza general, lo que permitió llevar a cabo los recursos necesarios para esta revitalización de la escena cultural nacional.

Tanto el gobierno socialista como los gobiernos de las diferentes comunidades autónomas, en la medida de sus posibilidades, intentaron modernizarse e invertir en cultura. Los grandes focos además de Madrid y Barcelona, fueron Andalucía, Valencia, País Vasco y Galicia. En todos ellos, a excepción del País Vasco, la pintura fue la técnica predominante usada por los artistas.

Durante esta década se inauguró la feria de Arte Contemporáneo de Madrid (ARCO) de la mano de la galerista Juana de Aizpuru en 1982 ${ }^{1}$. También en este ámbito se crearon otras iniciativas como ARTEDER en Bilbao o la feria Interarte en Valencia, fuera ambas del circuito artístico de la capital. Al mismo tiempo surgieron otro tipo de propuestas como las bienales que aunque tuvieron, al igual que las dos ferias que acabamos de mencionar, una duración efímera, sirvieron para acercar el

1 AIZPURU, Juana "Madrid, ciudad abierta", Lápiz, Madrid, 1983, nº 3, Febrero, p.9. 
arte contemporáneo a ciudades de provincias como ocurrió en el caso de Oviedo, Pontevedra, Zaragoza...

En cuanto a las exposiciones hubo una clara potenciación de muestras de artistas foráneos dentro de nuestros límites, principalmente en Madrid. Si durante los años setenta la Fundación Juan March había sido la encargada de mostrar en Madrid las propuestas más arriesgadas, en los años ochenta se sumarán a ella la Fundación Caja de Pensiones con sede en Madrid y Barcelona y con María Corral como directora artística, la reapertura del Círculo de Bellas Artes con un programa específico en el mundo de la divulgación artística y con el escultor Martín Chirino como director, la creación del Museo Reina Sofía... Todo ello nos indica una vez más, como este nuevo interés por el arte, sobre todo por el contemporáneo, se vio reflejado en una gran actividad por parte de iniciativas públicas y privadas que además de actuar como contenedores de las obras, las mostraban al gran público de la época.

Paralelamente fue muy importante también en esos años el intento por parte de los organismos, sobre todo públicos españoles, de promocionar el arte español fuera de nuestro país ${ }^{2}$.

Las galerías a su vez experimentaron un gran crecimiento, destacaron: Juana Mordó, Juana de Aizpuru, Fernando Vijande, Biosca, Buades, Heinrich Ehrhardt... que comenzaron a impulsar el coleccionismo de obras de arte, algo a lo que ayudó la supresión del impuesto de lujo que se aplicaba anteriormente a las obras.

Estas actividades fueron recogidas en numerosas revistas de la época especializadas que surgieron durante esos años, entre ellas hay que destacar la labor de algunas como Lápiz, La luna de Madrid, Buades, Batik, Guadalimar, Arteguía, Crítica de Arte, Revista Figura, el suplemento de artes de la Guía del ocio...

En relación a los creadores, la década de los años ochenta se caracterizó por una efervescencia artística, aparecieron en escena muchos jóvenes que recibieron un gran apoyo por ciertas entidades como la sala Amadis dependiente del Instituto de la Juventud madrileño. Muchos de ellos fueron englobados dentro de la polémica "Movida madrileña".

\section{Nueva York}

Al analizar la formación del grupo Estrujenbank comprobaremos cómo tres de los cuatro componentes del mismo residieron en Nueva York varios años en la década de los ochenta ${ }^{3}$.

Esta ciudad tras la segunda Guerra Mundial comenzó a recibir a numerosos intelectuales europeos quienes huían de una situación hostil que impedía que pudiesen desarrollar sus actividades. Gracias a ellos se fue generando un ambiente cultural

2 Se llevaron a cabo numerosas exposiciones: Eduardo Chillida y New Images from Spain en The Solomon R. Guggenheim y New Images from Spain: Works on paper en el Spanish Institute de esa misma ciudad americana. Nueva Figuración española expuesta en Cambridge en 1982, Arte español actual en Toulouse en 1984, Caleidoscopio español Arte joven de los 80 (Spanisches Kaleidoskop) vista en Alemania y en Suiza en el 84-85, Spansk Egen Art mostrada en el 84 en Suecia y Noruega, Europalia 85 en Bélgica...

3 Dionisio Cañas, Patricia Gadea y Juan Ugalde. 
en la ciudad norteamericana. Sin embargo según avanzaba la Guerra Fría esa buena relación existente entre el arte europeo y el americano comenzó a agrietarse debido a la lucha entre Nueva York y París por intentar el primero mantener y el segundo conseguir la hegemonía en el mundo del arte contemporáneo. Para ello en Estados Unidos trataron de crear un estilo propio desvinculado de influencias europeas surgiendo gracias a ello el expresionismo abstracto ${ }^{4}$.

A partir de entonces el mundo del arte cambió su mirada para dirigirla a esta ciudad, donde comenzaron a surgir las corrientes más interesantes.

A consecuencia de los acontecimientos históricos Nueva York se convirtió en una ciudad adaptada a las necesidades del arte contemporáneo, llegando incluso a condicionar la especulación inmobiliaria ${ }^{5}$. Los museos y las galerías más importantes del mundo se encontraban en sus calles.

Debido a esta influencia en el mundo del arte contemporáneo, muchos artistas extranjeros viajaron a la ciudad de los rascacielos para conocer de primera mano lo que en ella ocurría y para intentar, en la medida de lo posible, triunfar en un lugar en el que el mercado del arte tenía una estructura bien definida.

Al igual que Patricia Gadea y Juan Ugalde se fueron a Nueva York, otros muchos artistas españoles se trasladaron a la gran ciudad: Miquel Barceló, Chema Cobo, Victoria Civera, Antoni Muntadas, Mireia Sentis, Francesc Torres, Juan Uslé...Otros como José Guerrero o Esteban Vicente ya vivían allí desde hacía décadas, siendo referentes claros para los artistas españoles.

En una entrevista mantenida con Juan Ugalde, el artista explicaba qué significó para ellos la ciudad de Nueva York:

"En el mundo del arte era un lujo aquello, porque iba todo el mundo, los japoneses, los suizos... a comprar allí que había un macromercado. Se podían permitir ciertos lujos, poder hacer otras cosas mucho más arriesgadas. La diferencia era abismal en ese sentido"'.

Esto es algo esencial a la hora de entender la historia de Estrujenbank, la importancia que tuvo esta experiencia neoyorkina, puesto que tanto para Patricia Gadea como para Juan Ugalde significó un gran conocimiento de cómo los circuitos del arte funcionaban fuera de España.

\section{Formación Estrujenbank}

A pesar de que el inicio oficial del grupo Estrujenbank, consolidado como tal, lo situamos en el año 1989, a la vuelta de Patricia Gadea y Juan Ugalde a Madrid, existieron unas fases previas en las cuales se comenzó a gestar y a materializar poco a

\footnotetext{
4 GUILBAULT, Sergi. De Cómo Nueva York robó la idea de arte moderno, Tirant lo Blanch, Valencia, 2007.

5 NAROTZKY, Susana. "Nueva York East Village o donde la ciudad termina”, Lápiz, no 26, Junio, Año III, Madrid, 1985, pp.50-53.

6 Entrevista realizada a Juan Ugalde por la autora el 1 de julio de 2009 en Madrid.
} 
poco la idea de la formación del colectivo. Se podría dividir la historia del grupo en tres etapas.

\subsection{Primera etapa madrileña (1982-1986)}

La primera de estas fases corresponde a los años 1982-1986 y tuvo como escenario la ciudad de Madrid.

En el año 1982 Patricia Gadea y Juan Ugalde se trasladaron a vivir de El Escorial a la capital española, comenzando a participar activamente en la vida cultural de la misma, inserta por aquel entonces en pleno apogeo de la "Movida madrileña".

Instalaron su estudio en un bajo en el 143 del Paseo de Delicias en el barrio de Legazpi, espacio que posteriormente tuvo una gran importancia en la historia de Estrujenbank ya que en él abrieron en el año 1990 su sala de exposiciones.

Ya por aquel entonces comenzó su interés por el arte "underground" y trabajaron junto con otros artistas en una exposición clandestina organizada en el pasadizo del metro de Madrid que une el parque del Retiro con la calle Lagasca.

En esta época conocieron al también artista Mariano Lozano quien realizaba cuadros de temática popular, algo que le interesó mucho a Patricia Gadea por lo que decidieron trabajar juntos en algunos proyectos.

Fue en esas fechas cuando empezó a surgir la idea de formar un colectivo artístico en el que los tres artistas colaborasen; sin embargo la concesión de una beca a Patricia Gadea y a Juan Ugalde impidió que se llevase a cabo, ya que ambos se trasladaron en 1986 a Nueva York.

\subsection{Etapa neoyorkina (1986-1989)}

Esta etapa comienza con la marcha de Patricia Gadea y Juan Ugalde a Nueva York gracias al programa de becas Fulbright concedidas por el Ministerio de Cultura de España.

En dicha ciudad los artistas alquilaron un estudio en Canal Street, en la zona del East Village donde entraron en contacto con la zona artística más activa de la isla.

Fue allí donde conocieron a Dionisio Cañas que vivía en Nueva York desde el año 1973 y en la que trabajaba como profesor de literatura hispánica en la universidad.

Debido a su gran afinidad, muy pronto los tres se convirtieron en inseparables, comenzando a frecuentar los mismos ambientes. Su vida en común estuvo marcada por la efervescencia artística en el estudio, las salidas nocturnas, la vida en los bares, el trabajo y también el descubrimiento de la gran ciudad con todo lo que ésta les ofrecía.

Fue una constante en el grupo, que casi era tan importante la acción de trabajar en el taller todos juntos, como la de pasar tiempo divirtiéndose y charlando en cualquier bar de la zona que frecuentaban.

En 1987 Juan Ugalde y Patricia Gadea, tratando de resumir su experiencia de la beca, publicaron un libro de dibujos denominado Portraits en el que apareció por primera vez el logo Estrujenbank, en este caso como editora ficticia del libro. 
A lo largo de estos años comenzaron a retomar la idea de crear un colectivo incluyendo ya a Dionisio Cañas en el equipo, acordando debido a su formación como lingüista que actuase como teórico del colectivo.

En 1989 debido a problemas económicos y a ciertas complicaciones con la renovación del visado, Patricia Gadea y Juan Ugalde decidieron regresar a Madrid, quedándose en Nueva York Dionisio Cañas como corresponsal del grupo en la ciudad.

\subsection{Segunda etapa madrileña (1989-1992)}

Esta segunda etapa madrileña fue la época más importante del colectivo puesto que corresponde al período de consolidación definitivo del grupo, ya con todos sus componentes.

En el año 1989 Patricia Gadea y Juan Ugalde regresaron a España, estableciéndose en un principio en El Escorial y manteniendo su estudio en el Paseo de Delicias como lugar de trabajo.

Debido a la fuerte diferencia entre la realidad española y la neoyorkina que habían visto, decidieron buscar una vía de escape en el mundo del arte, replanteándose la idea de formar un colectivo que no persiguiese las modas artísticas de la época.

Juan Ugalde explicaba sus impresiones de la realidad española a su vuelta de Nueva York a Dionisio Cañas en una carta:

"Da la sensación de que en este país todo el mundo (al menos de nuestra edad) es ligeramente retrasado mental, con una sonrisa puesta y abrazando sus gintonics, a las máquinas de marcianos, a los panchitos, sin nada en absoluto de qué hablar o qué pensar, es como si tuviesen paralizados los sentimientos y todo continuase en una monotonía del "demasiao" "qué pedo" todo ello en pubs modernillos con música años setenta. Lo de la vuelta a España suena a "Qué he hecho yo para merecer esto" (...) Cada vez que vemos algo de Nueva York se nos revuelven las tripas y nos da la sensación de que estamos entrando sin darnos cuenta en un proceso de atontamiento y alcoholizamiento mecánico que invade el horizonte de nuestra vecindad"?.

En julio de 1989 Patricia Gadea y Juan Ugalde se pusieron de nuevo en contacto con Mariano Lozano, con el que habían hablado tres años antes acerca de la idea de formar un grupo, y al interesarle también a éste la propuesta comenzaron a colaborar todos juntos, pasando a denominarse: Estrujenbank, hojalatería y pintura en general. Los tres trabajaban conjuntamente en el estudio de Legazpi mientras que Dionisio Cañas les mantenía informado de todo lo que ocurría en Nueva York.

Tras una primera exposición conflictiva en la galería Buades el grupo comenzó a plantearse la idea de crear una sala propia, surgiendo así la sala de exposiciones Estrujenbank, que se inauguró en mayo de 1990.

7 Carta sin fechar de Juan Ugalde a Dionisio Cañas (1989). 


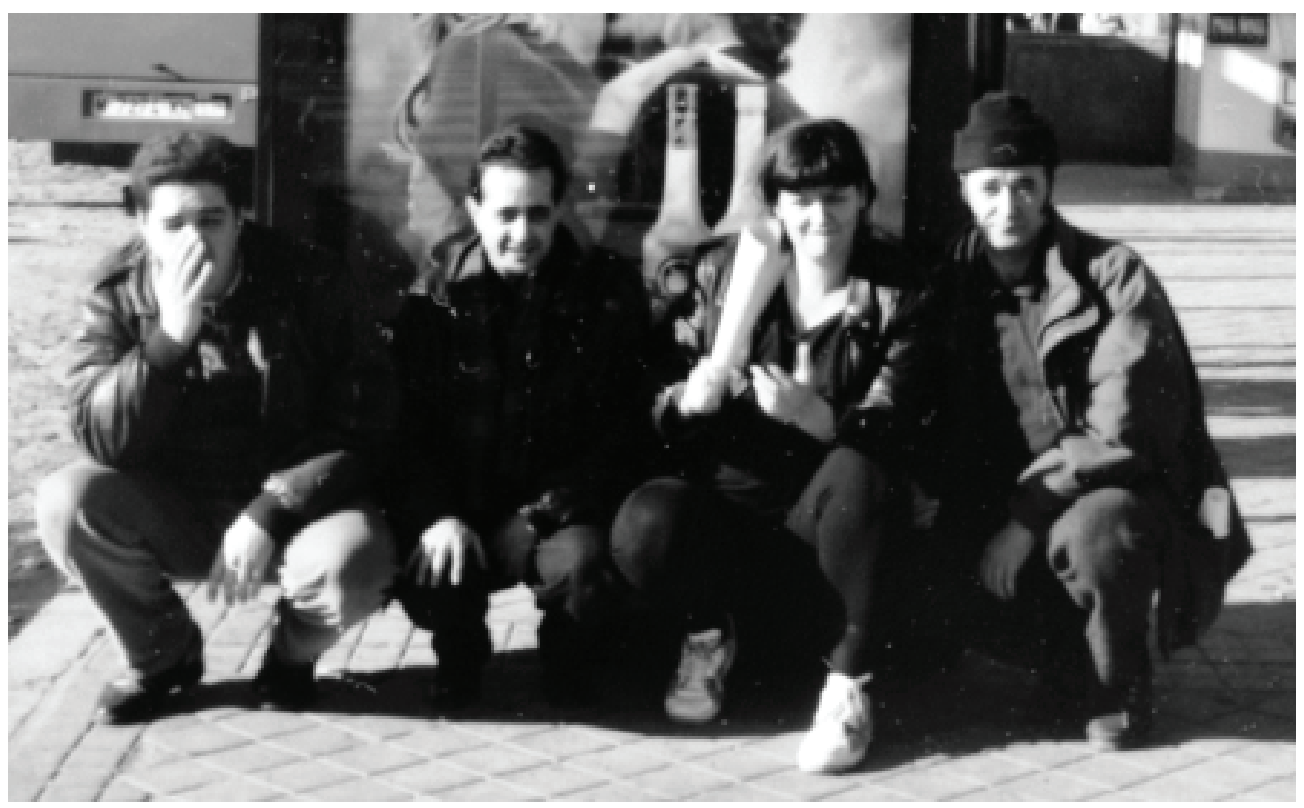

Fig. 1: De izquierda a derecha: Juan Ugalde, Mariano Lozano, Patricia Gadea y Dionisio Cañas.

Los objetivos de Estrujenbank quedaron reflejados en el catálogo de la exposición celebrada en la galería Xavier Fiel de Palma de Mallorca:

"Estrujenbank. Hojalatería y pintura en general tiene por objetivo la sublimación del entorno cotidiano como punto de partida para distintas operaciones de carácter socio decorativo político cultural. Por su específica estructura en el panorama artístico, Estrujenbank, hojalatería y pintura en general define su postura al margen del concepto histórico del artista individual. Y considera que sólo la colaboración y unión de individualidades hace posible un desarrollo artístico mínimamente digno para la existencia dentro del organigrama de la sociedad actual" 8 .

Los cuatros componentes del grupo coincidían en su disconformidad ante la situación artística española del momento, por ese motivo decidieron formar un colectivo artístico, al considerar que la creación en conjunto era la más adecuada para combatir el tipo de arte complaciente existente en la época.

Su objetivo principal era crear, a través del grupo y de sus acciones, una salida alternativa al arte contemporáneo español de finales de los años ochenta y principios de los noventa en Madrid, decidiendo actuar a través de diversos mecanismos contra la tendencia internacional que se estaba impulsando en España. Lo foráneo estaba de moda en nuestro país: el neoexpresionismo alemán, la transvanguardia italiana o

8 CAÑAS, D. Estrujenbank. Hojalatería y pintura en general, Galería Xavier Fiol, Palma de Mallorca, 1990 (sin paginar). 
el panorama americano eran algunas de las corrientes más mostradas en las grandes exposiciones ${ }^{9}$.

Otra de las decisiones del grupo fue crear varias revistas y escritos tratando de contemplar los temas culturales que les preocupaban y donde las críticas se mostraban sin reparo, puesto que no dependían de nadie, lo que les daba, al igual que ocurría en la sala, una gran libertad.

Trabajaron y realizaron varias obras plásticas conjuntamente, intentando acercar el arte a todo tipo de público; buscaban un arte comprensible por el pueblo. A través de este interés común por lo popular llegaron a estar muy vinculados con el mundo rural, sobre todo con el manchego del que procedía Dionisio Cañas. Dentro de este ambiente rural, en los bares de pueblo encontraron mucho material que luego utilizaron en sus obras o como inspiración de las mismas, dándoles un nuevo valor artístico.

Por otro lado, paralelamente a todas estas actividades también encontraron espacios donde exponer sus obras fuera de su sala, mostrando sus creaciones ante un público diferente al que solía acudir a su galería.

\section{Actividades del colectivo}

\subsection{Sala Estrujenbank}

En mayo de 1990 se inauguró en el número 143 del Paseo Delicias la Sala Estrujenbank como un espacio de exposición independiente con apertura al público sólo los fines de semana. Los días laborales estaban destinados, en un principio, al trabajo del equipo.

Dentro de la misma nave que albergaba la sala, se encontraba el estudio de los artistas, otro que alquilaban al también artista y amigo suyo Gonzalo Cao y a su vez este mismo espacio era la residencia de Patricia Gadea y Juan Ugalde, ya que para poder sufragar los gastos de los proyectos Gadea y Ugalde decidieron irse a vivir al estudio de Legazpi y alquilar la casa que tenían en El Escorial.

Aunque hubo dos excepciones con dos exposiciones individuales, la idea originaria era que en la sala sólo podían exponerse muestras colectivas.

Una vez decidido el tema de cada exposición, un comisario la llevaba a cabo y buscaban obras que encajasen con ese asunto. Los creadores debían presentar sus propuestas expositivas y ser aceptados por Estrujenbank antes de programar cada muestra.

Los recursos eran escasos puesto que todo corría a cargo de Patricia Gadea y Juan Ugalde por lo que el proyecto no era rentable económicamente. No recibían, ni tampoco era su intención, ningún tipo de ayuda o subvención que los ayudase a mantener la sala, aún así su galería permaneció abierta dos años.

Debido a la imposibilidad económica de realizar catálogos de las mismas, se elaboraban invitaciones con la máxima documentación posible para informar al público.

9 OLIVARES, Rosa, “La mitad de una década prodigiosa”, Lápiz, Madrid, Año V 1988, n50, Mayo-Junio, p.84-87. 
Patricia Gadea y Juan Ugalde se llevaban un dos por ciento de comisión si se vendía alguna obra expuesta en la sala. Por otro lado las ventas fueron muy escasas y con dicha comisión por cada venta no lograban sufragar los gastos. De cualquier manera esto formaba parte del espíritu con el que la sala Estrujenbank fue creada: no buscaban el beneficio material propio, sino que preferían un cambio de actitud de la gente ante el arte. Perseguían una respuesta radical al triunfalismo de la figura del artista como genio comercial y pretendían a través de la unión de sus fuerzas producir un cambio en la historia del arte español, en la que el arte popular que preconizaban alcanzase un nuevo valor.

$\mathrm{Al}$ igual que había ocurrido en la época de las vanguardias, querían romper con aquello que les rodeaba buscando una nueva salida a través de sus creaciones y de sus acciones.

Patricia Gadea explicaba a Sol Alonso en una entrevista en el periódico El País cómo ellos no habían creado la sala para exponer su propio trabajo sino el de gente con obras afines a su producción:

"Estrujenbank es un espacio alternativo creado para trabajar con los aspectos decorativos, sociopolíticos y culturales de Madrid. Exponer aquí nuestra obra nos parecía demasiado. Siempre son cosas de otros, pero forma parte de nuestra dinámica de trabajo" 10 .

Con el paso del tiempo la sala se fue convirtiendo en un lugar de encuentro de muchos artistas de todas las edades que encontraban en su interior, un espacio donde las normas no existían, en el que eran bien recibidos y en el cual podían observar e incluso exponer obras que no lograban ver en ningún otro sitio. Disponían de una libertad total al no depender económicamente de nadie, lo que se veía reflejado en sus creaciones, pudiendo mostrar obras "políticamente incorrectas" sin ninguna censura por parte de los comisarios de las exhibiciones.

Patricia Gadea y Juan Ugalde financiaron tanto la sala como todos los proyectos que en ella se desarrollaban. Juan Ugalde comentaba cuáles fueron las razones que llevaron al cierre de la sala:

"Se rompe por muchas razones, Patricia y yo nos separamos, estábamos agotados, la sala nos tenía desbordados, económicamente todo era inviable, ya habíamos llegado al nivel de que habíamos pedido préstamos a todo el mundo, y aquello no tiraba por ningún lado. Y bueno Mariano se había ido, se fue mucho antes, Dionisio también se había vuelto a Nueva York, en fin, y básicamente la separación...”"11.

La sala Estrujenbank se creó en un barrio obrero de Madrid, el barrio de Delicias, en el que no había tradición artística, una zona algo alejada del centro. La sala inten-

\footnotetext{
10 ALONSO, Sol. "El goce urbano. De las perversiones", El País, 24 de septiembre de 1990. www.elpais.

11 UGALDE, Juan. Entrevista.
} com. 
taba acercar las obras de arte a la gente del pueblo, revolucionando de esa manera la vida del barrio ${ }^{12}$.

Por otro lado el hecho de que Patricia Gadea y Juan Ugalde fuesen artistas encaja con la visión del creador desencantado que busca una alternativa al mercado que lo rodea y lo asfixia (do it yourself), si no existe lo que buscas, créalo tu mismo y exactamente fue eso lo que hicieron con esta sala de exposiciones.

Las muestras que se llevaron a cabo en la sala fueron las siguientes:

-Callos de la casa (25 de mayo-30 de junio de 1990).

-Animales politicos (21 de septiembre-13 de octubre de 1990).

-La nada de la política (26 de octubre-17 de noviembre de 1990).

-La política de la nada. (30 de noviembre-28 de diciembre de 1990).

-Instalación: Margo Turewicz y Mirek Filonik (Febrero- 1 de marzo de 1991).

-PSOE (1 de marzo-27 de abril de 1991).

- ¿Dónde está mi ropa? ¿Cómo llegué aqui? (17 de mayo-29 de junio de 1991).

-El fin de las razas felices (8 de noviembre-21 de diciembre 1991).

-Envidiamierdarezanadabar (17 de enero-29 de febrero 1992).

Y también realizaron un festival de vídeo:

-VIDEO A.V.E. (30 de noviembre-28 de diciembre de 1991).

Las exposiciones que en ella se organizaron sirvieron también como nexos de unión de diversos grupos artísticos, como E.M.P.R.E.S.A. y Libres Para Siempre que pasaron a formar parte de la "familia Estrujenbank" y los acompañaron a lo largo de su recorrido.

En Febrero de 1992 Patricia Gadea y Juan Ugalde pusieron fin a su relación sentimental y anunciaron unas vacaciones indefinidas, lo que significó el final de la sala Estrujenbank; aunque como veremos más adelante no fueron las últimas actividades que se desarrollaron en ese espacio donde tendrán lugar la tercera edición de Doméstico y también se celebró el Festival 123 Delicias de videoarte.

\subsection{Exposiciones fuera de la sala}

La labor del grupo no se limitaba a las actividades realizadas en la sala, sino que contemplaron diversos proyectos fuera de la misma.

- Galería Buades

La primera exposición del grupo en sociedad En un planeta remoto hace ya mucho tiempo se vio frustrada por un malentendido.

Era el mes de diciembre de 1989 y en la Galería Buades, que trabajaba habitualmente con Juan Ugalde, era el lugar donde se iban a mostrar sus creaciones, sin embargo, en el catálogo apareció sólo el nombre de Juan Ugalde y el logo de Estru-

\footnotetext{
12 En la actualidad está ocurriendo algo similar al haber creado varios centro de arte contemporáneo en la zona: La Casa Encendida, el Matadero y también en febrero de 2010 en Legazpi tuvo lugar la primera edición de la feria de arte contemporáneo de Just Madrid, como competidora de la feria ARCO.
} 


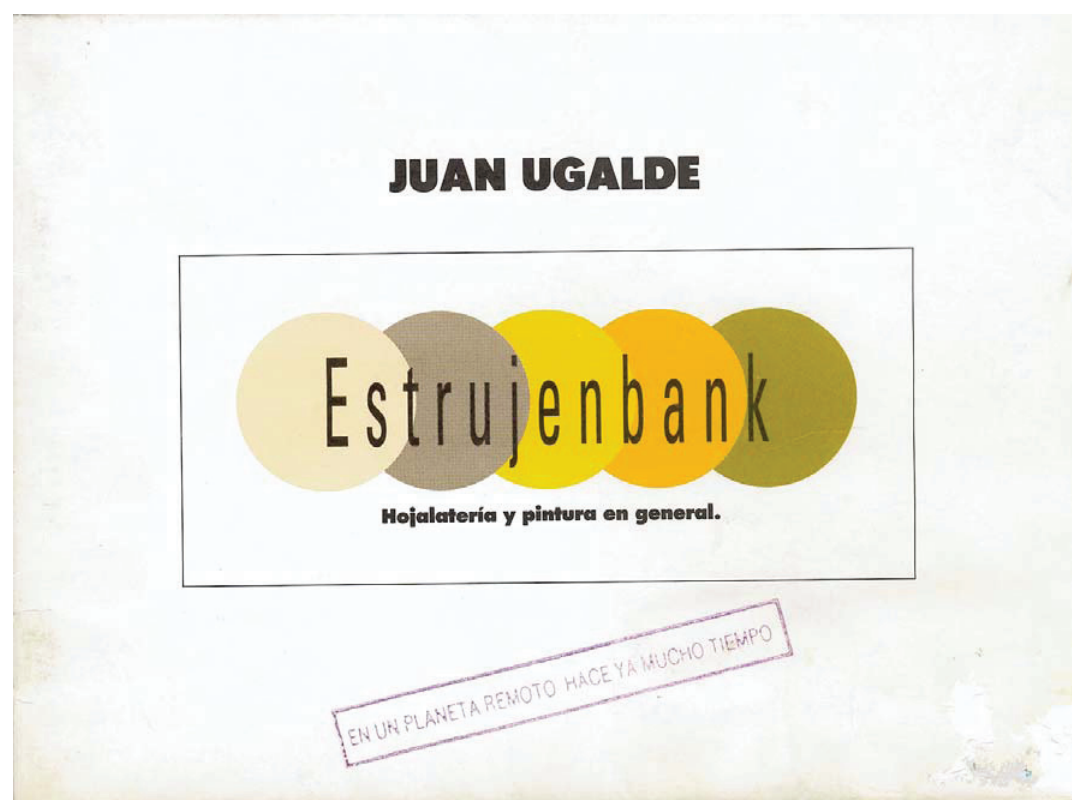

Fig. 2: Invitación de la exposición "En un planeta remoto hace ya mucho tiempo".

jenbank, lo que llevaba a la lógica confusión de que Estrujenbank era el título de la exposición individual de Juan Ugalde, y así fue recogido en la prensa de la época.

"De entrada, la muestra de Juan Ugalde (Bilbao, 1958) se presenta como una provocación en toda regla. El catalogo lleva en su cubierta un anagrama como tarjeta de crédito "Estrujenbank", y el lema "Hojalatería y pintura en general", y un sello que dice 'En un planeta remoto hace ya mucho tiempo"” 13 .

Los motivos apuntan a un malentendido intencionado por los dueños de la galería, convencidos de que una exposición individual de Juan Ugalde en solitario iba a ser mucho más rentable que una de un grupo que nadie conocía, ya que acababan de formarse.

\section{- ARCO 1990}

Tras las primeras discrepancias con la galería Buades, sus dueños confiaron en el colectivo y les invitaron a participar en su stand de la Feria Internacional de Arte Contemporáneo de Madrid: ARCO en febrero de 1990.

En ella expusieron su cuadro Decora tus mejores sueños y también una camiseta con el logo del grupo. La participación en la feria ARCO fue muy importante para el colectivo puesto que ésta era el mayor escaparate de arte contemporáneo que había en España, y era una forma de mostrar su obra al gran público y darse a conocer.

13 J.M.B. "Juan Ugalde, S.A.” $A B C, 4-1-1990$. 
- Sala Amadis

En febrero de 1990 Estrujenbank también participó en una exposición colectiva en la Sala Amadis. La muestra recibió el nombre de Made in USA. En esta exposición se mostraron además de las obras de Estrujenbank, creaciones de los artistas Pilar Insertis, Din Matamoro y Antonio Gómez Bueno, permaneciendo abierta al público desde el 9 de febrero hasta el 3 de marzo ${ }^{14}$.

- Galería Xavier Fiol

Durante marzo y abril de 1990 Estrujenbank mostró sus obras en la galería mallorquina de Xavier Fiol.

En el cartel que anunciaba la exposición, de nuevo aparecía el nombre de Juan Ugalde como artista de la exposición y dentro del propio catálogo el suyo era el único Curriculum Vitae que se mostraba, creando confusión una vez más en el receptor, al que no se le informaba correctamente de que la exposición trataba sobre un colectivo.

Uno de los acontecimientos más importantes de esta muestra fue la publicación del texto de Dionisio Cañas: Una mosca en la leche en el catálogo de la misma, uno de los escritos más importantes en la historia del colectivo. En él su autor manifestaba que Estrujenbank era la mosca en la leche del arte contemporáneo español, debido a sus actos y creaciones en las que no dudaban en mostrar su disconformidad con lo que ocurría en el arte contemporáneo español y cómo éste era gobernado por la gente acomodada de la época que dictaba las modas que los artistas debían seguir.

\section{- Galería Válgame Dios}

En la galería madrileña, ubicada en la calle homónima, se celebró una exposición colectiva en la que Estrujenbank participó junto a otros grupos como Libres Para Siempre.

La exposición recibió el título de Parece todo muy amistoso y Estrujenbank presentó solamente una pieza en la misma, ya que la colectiva fue muy amplia.

\section{- Fundació Caixa de Pensions de Valencia}

Esta exposición será la última en la que participen los cuatro componentes del grupo, puesto que tras ella Mariano abandona el colectivo.

Bajo el título Colección 90-91 Estrujenbank mostró sus obras en la Fundació Caixa de Pensions de Valencia. Es muy importante en este caso el lugar expositivo, ya que precisamente era una fundación de un banco, un espacio institucional que habitualmente criticaban pero en el que sin embargo aceptaron exponer, pasando a formar parte del sistema del mercado del arte al que tanto rechazaban.

A pesar de mostrar en la Fundació siguieron exponiendo sus temas propios, siendo la gente de pueblo, insertada en los cuadros mediante fotografías, los protagonistas y tratando de acercar sus cuadros a todo tipo de visitantes de la exposición,

14 “Espectáculos" $A B C, 16-2-1990$. 
huyendo del arte culto incomprensible que rechazaban continuamente. Buscaban el entendimiento por parte del receptor, huyendo del arte con tintes cosmopolitas.

- ARCO 1991

La galería Buades volvió a confiar en el grupo y los invitó a participar nuevamente en la feria de arte contemporáneo ARCO en el año 1991 donde presentaron cuatro cuadros.

\section{- Galería Studio Cristofori.}

Por primera vez Estrujenbank expuso en una galería extranjera, concretamente la galería Studio Cristofori que se encontraba en Bolonia.

La muestra tuvo lugar en mayo de 1991 y recibió el nombre de Strettamente Personale (Estrictamente personal).

Debido a problemas económicos ningún miembro del grupo pudo acudir al montaje ni tampoco a la exposición.

- Galería Fernando Durán

En diciembre de 1991, el grupo participó en una exposición colectiva en la galería madrileña Fernando Durán Arte Contemporáneo.

- Galería Magda Bellotti

En la galería Magda Bellotti de Algeciras, Estrujenbank presentó su exposición Pinturas y fotografías.

En el folleto de la exposición se publicaron a su vez cuatro textos escritos por el grupo: "Juegos de artificio España 1492-1992", "I love analfabetismo", "El totalitarismo dulce" y "Un día cualquiera".

\section{- Estrujencuenca}

En marzo de 1993 a pesar de que el grupo como tal ya no se encontraba en su período de máxima actividad, teniendo en cuenta que la galería permanecía cerrada y que sus componentes no trabajaban tampoco juntos tras la separación de Patricia Gadea y Juan Ugalde, los cuatro miembros originarios del colectivo se volvieron a reunir para realizar un taller en la Facultad de Bellas Artes de Cuenca.

La relación existente entre varios profesores dicha facultad (Simeón Saiz, Gonzalo Cao...) y el grupo Estrujenbank había sido muy importante, motivo por el cual fueron invitados para impartir un taller al que acudieron numerosos estudiantes de la misma.

Siguiendo los preceptos Estrujenbank los artistas proporcionaron un carrete de fotos a cada participante y éstos últimos debían salir por la ciudad de Cuenca a realizar fotografías y a recoger cualquier tipo de material que les interesase, para reunirlo todo posteriormente en una exposición que se realizó en los propios pasillos de la facultad. En definitiva era la elaboración de un gran collage colectivo realizado con materiales diversos. 
Era esta una iniciativa al más puro estilo duchampiano y su concepto del ready made, en el que cualquier material encontrado podía ser expuesto como una obra de arte, convirtiendo objetos cotidianos, en este caso rescatados de la calle a los que les añadían pequeñas modificaciones, en verdaderas piezas artísticas al sacarlas de su contexto habitual y exponerlas ante un público. El sitio en el que se ubicaban estas obras condicionaba también los objetos expuestos convirtiéndolos en obras de $\operatorname{arte}^{15}$.

\section{- Arte colectivo español}

En marzo de 1994 Estrujenbank participó de nuevo en una exposición colectiva, esta vez en el Espace d'Art Mille Feuilles en La Marsa (Túnez) y comisariada por Patricia Gadea.

En la muestra participaron Agustín Parejo School, Estrujenbank, Preiswert, E.M.P.R.E.S.A., Cielo y Libres Para Siempre.

\section{- MACBA.}

En marzo de 2005 se mostró en el Museo de Arte Contemporáneo de Barcelona y posteriormente en Granada en el Centro José Guerrero la exposición Desacuerdos. Sobre arte, políticas y esfera pública en el Estado Español en dicha muestra fueron muchos artistas y colectivos los que participaron

Como punto de partida de la exposición se encontraba el año 1969 con los Encuentros de Pamplona y hacía un recorrido por la historia del arte español de los setenta, ochenta y noventa analizando diferentes posturas críticas y novedosas a lo largo de esos años en nuestro país ${ }^{16}$.

\subsection{Performances}

En los planteamientos iniciales del grupo, sus componentes siempre habían contemplado la posibilidad de realizar sus creaciones utilizando todo tipo de manifestaciones artísticas:

"El colectivo no estaba planteado como un grupo que hiciera exclusivamente una obra plástica, sino también como un engranaje con el que acometer proyectos de diversa índole: fotografía, vídeo, performances, acciones, textos..." ${ }^{17}$.

\section{- Metrópolis}

Para el programa Metrópolis de Televisión Española, Estrujenbank realizó cuatro anuncios en octubre de 1990 .

15 Directamente vinculado con estas experiencias nos encontramos con un proyecto que ha desarrollado Dionisio Cañas a lo largo de estos últimos años llamado "El Poema de Nadie" donde ayudado por numerosos voluntarios recorren las calles de diversas ciudades recogiendo palabras abandonadas que les interesan, y posteriormente se reúnen para juntarlas en un gran collage formando un poema.

16 AA. VV. Desacuerdos. Sobre arte, politicas y esfera pública en el Estado Español. Coeditado por la Diputación de Granada, MACBA, Arteleku y Unia, 2005.

17 www.estrujenbank.es 
El programa trataba sobre grupos de artistas españoles e italianos y Estrujenbank fue uno de los elegidos para llevar a cabo las acciones.

Más que una performance improvisada, llevaron a cabo varias actividades siguiendo un guión, por lo que la respuesta del público no tenía mucha importancia en el momento del desarrollo, al haber sido creados para ser emitidos por la televisión.

Los anuncios grabados fueron los siguientes: "Los banqueros también ganan", "La opción que le da más tanto por ciento de interés", "Ganamos cuando usted gana" y "Distinguido y elegante". Todos estos títulos tienen una relación directa con el propio nombre Estrujenbank y su vinculación con el mundo de la crítica de los bancos.

- Campaña para la desinformación y el analfabetismo I

El grupo Preiswert Arbeitskollegen fue quien organizó la convocatoria y los componentes del grupo Estrujenbank, inmersos por aquel entonces en la elaboración de una muestra para el pabellón de Andalucía de la Exposición Universal de Sevilla de 1992, llevaron a cabo esta performance con el material que ya tenían.

La acción fue llevada a cabo en la estación de Atocha y consistía en ir disfrazados con una nariz de payaso y una peluca, llevando a modo de "hombre anuncio" un cartel colgado en el que aparecía la frase: "Campaña para la desinformación y el analfabetismo", y bajo ella una parodia de todo lo que era el 92 para ellos.

El grupo a través de esta acción buscaba la interacción con el público repartiendo a la gente con la que se encontraba en la estación y en los vagones del metro, octavillas en las que mostraban información acerca de la campaña.

\section{- Campaña para la desinformación y el analfabetismo II}

Esta campaña la llevaron a cabo ya en Sevilla, que era el lugar originario para el que había sido pensada. Formaba parte del proyecto "Plus Ultra" organizado por la comisaria independiente Mar Villaespesa para el pabellón de Andalucía. En este proyecto participaron otros artistas con diferentes obras como Soledad Sevilla, José María Larrondo o Francesc Torres.

La campaña se mostró tanto en el interior del pabellón de Andalucía de la Exposición Universal como en las calles de la ciudad hispalense y consistía en poner pegatinas por toda la ciudad con el eslogan "I love analfabetismo", hombres-sandwich paseándose por Sevilla con grandes cartelones con fotos repartiendo octavillas, vídeos de entrevistas con analfabetos que se presentaron en la Sala de exposiciones de Luis Cernuda y también un montaje y fotos sobre el tema. ${ }^{18}$

El objetivo de esta campaña era manifestar su interés hacia el analfabetismo socio cultural, es decir crear una campaña que promoviese la desinformación y el analfabetismo. Defendían un analfabetismo que permitiese poder juzgar sin poseer ningún conocimiento, pudiendo de esa manera no estar influenciados y dirigidos por la clase dirigente o culta del país. Consideraban al resto de la población, a todos aquellos no analfabetos originariamente, tal cual lo entendemos hoy en día, analfabetos de

18 CAÑAS, D. LOZANO, M. y UGALDE, J. Tot Estrujenbank, Hojalatería y Pintura en general, El Garaje Ediciones, Madrid, 2008, p 122. 
verdad ya que sólo seguían los dictámenes de la época sin darse cuenta de lo que de lo que sucedía realmente.

- Casa de América de Madrid.

En abril del año 2003 coincidiendo con la reedición de su libro Los tigres se perfuman con dinamita por Ediciones Originales, se realizó una presentación del mismo en la Casa de América en Madrid.

Para la ocasión los cuatro componentes originarios del grupo se volvieron a reunir, decidiendo realizar una performance en Madrid.

La acción consistía en dar un paseo por las calles de la ciudad, en la cual los cuatro artistas salían con una especie de caja en la cabeza, agujereada en la boca y en los ojos. Mientras ellos caminaban, una quinta persona les grababa. La performance concluía cuando los cuatro artistas entraban en la sala de la presentación del libro y en ese lugar se encontraban con los asistentes al acto que estaban viendo el vídeo grabado de la caminata, lo que suponía una continuidad de la actividad.

En la presentación el concepto de la performance giraba en torno a la misma idea, la del gran hermano que todo lo ve, primero eran los artistas los observados, ya que un cámara iba grabando todo lo que hacían, y sin embargo cuando entraban en la sala eran ellos los que observaban al público que a su vez estaba viendo lo que ellos hacían en la grabación, demostrando la teoría de que nadie está a salvo de ser vigilado $^{19}$.

\subsection{Cambio de Sentido, Cinco Casas}

Dentro de la historia del colectivo, la exposición Cambio de Sentido en Cinco Casas fue una de las actividades con mayor repercusión realizadas por el equipo en su época, así como una de las más conocidas hoy en día.

Cambio de Sentido fue comisariada por Dionisio Cañas en el pequeño pueblo manchego Cinco Casas (Ciudad Real).

La muestra estaba planteada como una exposición de colectivos que acudían a Cinco Casas para mostrar sus creaciones. El espacio expositivo era el salón de baile del pueblo y la celebración de la muestra coincidía con las fiestas patronales de San Isidro, el 11 de mayo de 1991.

La idea principal de este cambio de sentido era descentralizar la idea del arte contemporáneo español que se exhibía habitualmente en Madrid y Barcelona como centros neurálgicos de la escena artística, y llevar las propuestas más arriesgadas del momento a un pequeño pueblo manchego para mostrarlas a sus habitantes.

Intentaron enfrentar ese arte a la gente del pueblo, alejando la idea de arte como mercancía. Por otro lado le quisieron dar un nuevo sentido a la actividad creadora:

19 Esta acción tiene cierta similitud con un texto no editado de Dionisio Cañas "Verania" escrito tras los sucesos del 11 de Septiembre de 2001 en Nueva York, ciudad en la que él residía por aquel entonces. En el escrito Dionisio Cañas critica la dura vigilancia ejercida por el poder en esa ciudad, por lo que el protagonista de su historia, que es él mismo decide ponerse una cabeza cúbica llena de espejos y caminar por las calles de la ciudad, para que todo aquel que lo observe se vea a sí mismo. 
deseaban que el pueblo captase y comprendiese ese arte, unas obras que no entendiesen de clases sociales de ningún tipo.

Dionisio Cañas comentaba cuál era el objetivo de la exposición:

\begin{abstract}
"Aunque en su origen no había ningún planteamiento teórico para realizar aquella exposición, si partíamos de una idea fundamental: hay que sacar el arte más actual para que le dé el aire, hay que sacar el arte de ese campo de minas color de rosa que son las galerías, los museos, las instituciones, hay que sacarlo de ese ciego ir hacia delante por las autopistas del negocio del arte y de su instrumentalización política, hay que tomar la primera señal de tráfico que nos encontremos y salirse de la autopista del arte; y la señal que apareció fue "Cambio de sentido". Y así lo hicimos, partimos de esta señal de tráfico y en las servilletas de papel de un bar de carretera rural diseñamos una exposición, un evento, un acontecimiento que esperábamos cambiara algo, si no el mundo, por lo menos que intentara llamar la atención de la crítica especializada sobre el hecho de que el arte de aquel momento no sólo se debía presentar en las grandes ciudades, donde se asumía que ocurriera todo lo nuevo, todo lo que podía renovar la dirección del arte de aquellos años noventa del siglo pasado, sino que en un pueblo rural también se podía exponer lo que para nosotros era el arte más interesante de aquel momento" 20 .
\end{abstract}

Los grupos que participaron en esta muestra fueron además de Estrujenbank, Agustín Parejo School, E.M.P.R.E.S.A., Libres Para Siempre, De-2, 03 COSAS, Equipo Límite, Tipolini Teck y Preiswert.

Los artistas que allí acudieron lo hicieron con sus propios medios, ya que nada era subvencionado y todo corría a su cargo, sin embargo las familias del pueblo acogían a los artistas en sus propias casas, por lo que no tuvieron que invertir en alojamiento. Este hecho indica el entusiasmo del propio pueblo en un principio con esta exposición.

Los preparativos transcurrieron sin problemas. Dionisio Cañas solicitó la colaboración ciudadana pidiendo a los habitantes del pueblo que quisiesen participar en el proyecto, que llevasen al salón de baile fotos familiares para exponerlas todas juntas, al lado de las obras de los colectivos que habían acudido a Cinco Casas. Ante la sorpresa del organizador muchos fueron los que se sumaron con sus recuerdos impresos a esta iniciativa.

Tras esta cordialidad y cooperación inicial el día previo a la inauguración el grupo E.M.P.R.E.S.A. colgó uno de sus cuadros con el que llegó la polémica. Tras la frase "El terror es nuestra forma de ser" expusieron varias fotografias de hombres desnudos, causando la indignación entre muchos de los hombres del pueblo que veían en esta obra un acto de provocación.

Ante tal estado de crispación, el alcalde del pueblo habló con Dionisio Cañas pidiéndole que retirase la conflictiva obra pero el poeta no accedió y decidió descolgarlas todas evitando así actuar como un censor. La única obra que se mantuvo fue la formada por las fotografías aportadas por la gente del pueblo.

20 CAÑAS, Dionisio. Cambio de sentido, Manuscrito inédito, agradezco al autor el haberme facilitado la consulta de este texto. 
Al enterarse de lo sucedido los artistas que habían acudido al evento se sintieron decepcionados e incluso hubo ciertos choques con los grupos más reaccionarios del pueblo, quedando todos ellos, afortunadamente, en una anécdota.

Cambio de Sentido tuvo una gran repercusión en la prensa de la época que se hizo eco de esta iniciativa. En algunos medios como en el periódico El Mundo llegaron a afirmar que habían sido los vecinos quienes habían optado por arrancar los cuadros en un acto que les descalificaba por sí mismo ${ }^{21}$ algo que como hemos visto no es cierto.

El resultado final de la exposición no resultó lo que se esperaba, puesto que el cambio que mencionaban no fue tal. La exposición no llegó a mostrarse, fue censurada antes de su inauguración, pero sin embargo supuso un importante primer acercamiento del arte contemporáneo a un espacio en el que nunca se había dado.

La oposición no fue general y a mucha gente del pueblo le entusiasmó la iniciativa. Además, de todas las obras expuestas, tan sólo una incomodó a algunos receptores, por lo que el resultado no fue tan negativo como pudiese parecer.

\section{Producción Estrujenbank}

\subsection{Obra plástica}

Estrujenbank. Hojalatería y pintura en general fueron un colectivo que llevaron a cabo principalmente obras pictóricas.

A igual que otros grupos como el Equipo 57, Equipo Crónica o Equipo Realidad, Estrujenbank realizaban las obras en conjunto siendo la labor de sus componentes de igual importancia durante el proceso de creación.

Los tres artistas plásticos: Patricia Gadea, Mariano Lozano (hasta 1991) y Juan Ugalde, se reunían durante la semana en el estudio de Legazpi y allí realizaban sus creaciones en equipo.

Uno de los motivos por los cuales Mariano Lozano asegura que se fue alejando del grupo, es porque según él, se dejó de $\operatorname{pintar}^{22}$ por lo que le dejó de interesar el proyecto.

Además también hay que recordar que Dionisio Cañas, excepto el año 1991 que disfrutó de un año sabático en España y en el que participó aportando collages y fotografías, el resto de tiempo vivía en Nueva York, por lo que la colaboración artística directa era imposible, centrándose, sobre todo, en sus labores de ideólogo del equipo.

En cuanto al trabajo en el taller, los artistas preparaban sus lienzos compuestos por grandes telas y utilizaban una brocha gorda para intentar imitar el proceder de los artistas amateurs usando también pintura acrílica industrial.

En casi todas sus obras insertaban elementos ajenos a la pintura como es el caso de las fotografías o de los eslóganes que utilizaban para criticar diversos aspectos de la sociedad actual.

\footnotetext{
${ }^{21}$ CAÑAS, D, LOZANO, M. y UGALDE, J. Op. Cit., p. 92.

22 Conversaciones con Mariano Lozano posteriores a la entrevista realizada por la autora en Madrid el 30 de junio de 2009.
} 


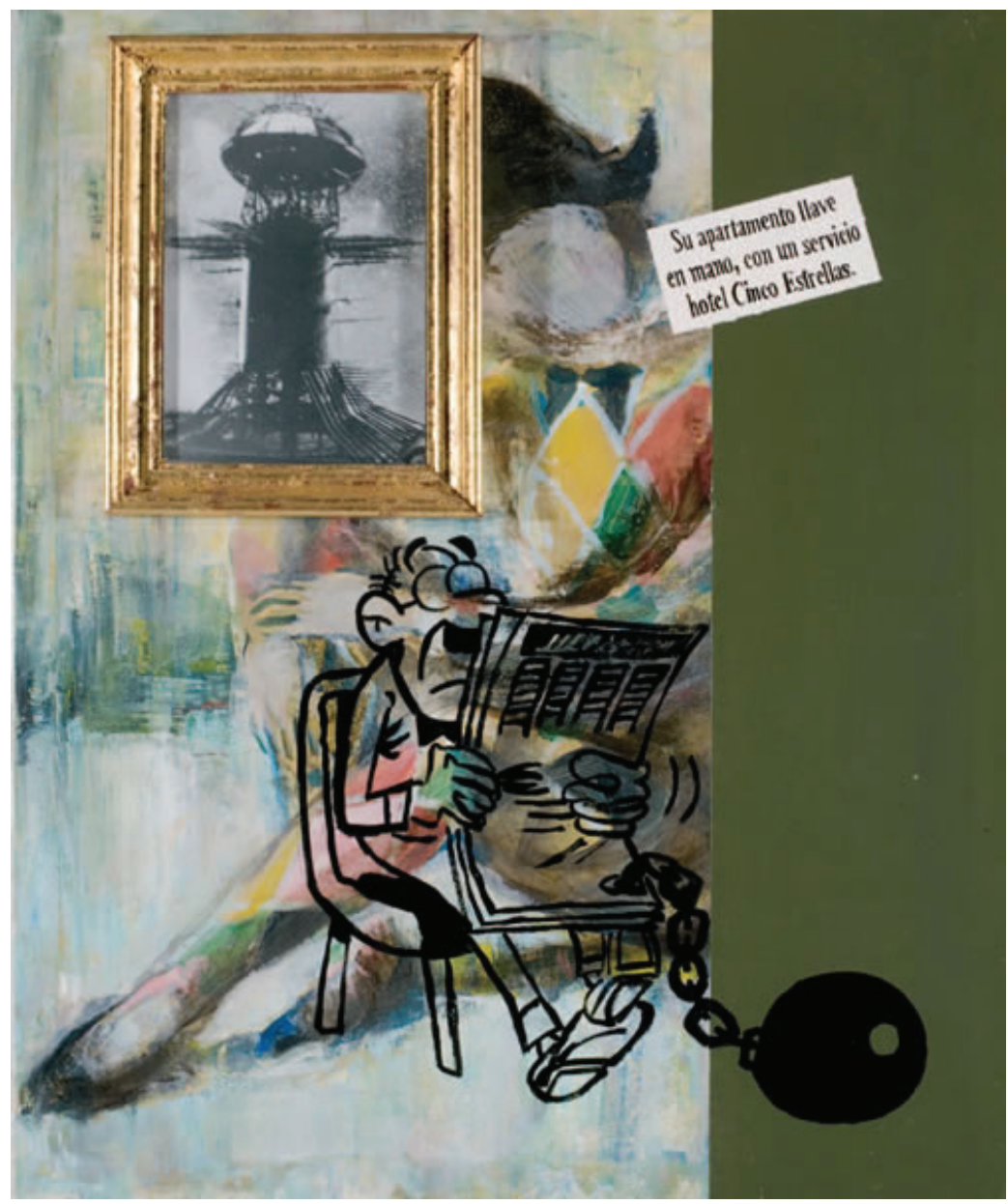

Fig. 3: Estrujenbank. Llave en mano, 1990. Técnica mixta sobre tela.

Se conservan numerosas obras del grupo, aunque desafortunadamente otras muchas han desaparecido.

En cuanto a la temática el grupo sintió siempre una gran predilección por los temas populares, lo español, denunciaron también el papel de la mujer en la sociedad de la época o la especulación mobiliaria. Para ellos fue muy importante también las influencias del mundo del cómic, puesto que en sus obras aparecían insertados a menudo figuras muy conocidas del cómic español, en especial personajes creados por Francisco Ibáñez y también era muy corriente el uso de eslóganes propios del mundo publicitario.

El propio logo del colectivo fue usado como una marca, ya que aparecía sustituyendo a la firma de autoría. 


\subsection{Obra literaria}

El colectivo Estrujenbank contempló desde sus inicios la literatura como una parte más de su producción artística, más teniendo en cuenta que entre sus componentes se encontraba un poeta. Dionisio Cañas ejerció en el resto de sus compañeros una fuerte influencia a la hora de prestar atención a todo aquello vinculado con el mundo de las letras.

El lenguaje escrito aparecía insertado en sus obras donde eran muy comunes los juegos de palabras procedentes del ámbito de la publicidad, utilizándolas como camuflaje de su directa ironía. Baste como ejemplo el slogan de "Estrujenbank, Hojalatería y pintura en general" u otro tipo de frases como "Ganamos cuando usted gana", "la opción que le da más interés"...

Su producción literaria fue extensa y publicaron varias revistas, numerosos textos y dos libros muy importantes en la historia del colectivo que fueron Los tigres se perfuman con dinamita publicado en 1992 (reeditado en 2003) que recogía las preocupaciones que compartía el grupo a principios de los años noventa y Tot Estrujenbank, hojalatería y pintura en general, ya sin la presencia de Patricia Gadea, pero dedicado a su memoria; un libro, donde a modo de guía, el grupo nos acerca a su historia, contada a través del testimonio de amigos, de artistas que colaboraron con ellos y del suyo propio.

\section{Disolución del grupo}

El primero que abandonó el grupo fue Mariano Lozano tras la exposición en la Fundació Caixa de Pensions en enero de 1991.

Tras la baja de Mariano Lozano, Estrujenbank siguió existiendo llevando a cabo un gran número de proyectos y formando parte de él: Dionisio Cañas, Patricia Gadea y Juan Ugalde.

Sin embargo fue a partir de la ruptura de Patricia Gadea y Juan Ugalde cuando el grupo se fue disolviendo poco a poco, puesto que con los dos verdaderos motores del grupo separados, las actividades se convirtieron en puntuales.

El mayor impacto se sintió en la galería que cerró sus puertas por vacaciones indefinidas, no volviendo a mostrar ninguna exposición comisariada por Estrujenbank.

Las muestras en las que participaron posteriormente fue con material ya realizado con anterioridad, por lo que no volvieron a trabajar juntos en el estudio; comenzando de hecho de nuevo su carrera individual.

Muy importante en la historia de este colectivo fue la influencia ejercida por ellos en otros grupos que se fueron formando en torno a la sala Estrujenbank, llegando a formar una especie de familia artística. Grupos como E.M.P.R.E.S.A., Libres Para Siempre o Preiswert crecieron junto a Estrujenbank compartiendo todos los mismos preceptos en torno a la idea de la actividad artística y a la realización de un arte no 
complaciente, un arte que buscase una reflexión por parte del espectador acerca de la sociedad en la que vivían.

En relación directa con lo que significó Estrujenbank y sobre todo su sala expositiva se creó el Festival de vídeo 143 Delicias en la antigua sala Estrujenbank donde se celebró hasta el año 2003.

La despedida definitiva de la Sala Estrujenbank, como indica el siguiente fragmento, fue la exposición Doméstico 02. Siete estudios en una nave.

"La nave del Paseo de las Delicias número 143 tenía una historia muy vinculada al arte. Había sido estudio de artistas durante casi veinte años y espacio en el que tuvieron lugar iniciativas como el colectivo Estrujenbank o el Festival de Vídeo 143 Delicias. El paso de Doméstico bajo su bóveda fue una forma de homenajear y compartir esa memoria" 23 .

Tras esta muestra la sala del 143 Delicias se cerró definitivamente al público, dejando tras de sí una parte de la historia del arte alternativo en España muy importante.

\section{Conclusiones}

A lo largo de este artículo hemos tratado de recuperar un legado que tiene un especial interés al mostrar la vitalidad que había en Madrid a finales de los años ochenta y principios de los noventa; intentando reconstruir y poner en valor el grupo Estrujenbank y su proyecto.

1. Los años ochenta se caracterizaron por una mirada hacia el exterior en un intento por recuperar todo aquello que la sociedad española no había podido disfrutar en época de la dictadura y más concretamente en el período de la autarquía. Al mismo tiempo se produjo un gran interés por mostrar lo que los artistas españoles hacían al mundo entero, por ello se organizaron varias exposiciones a lo largo de la década en el extranjero, intentando conseguir con ellas buena publicidad para nuestro país.

2. Nueva York fue uno de los destinos preferidos por los jóvenes artistas españoles, quienes fascinados por la importancia que en esa ciudad había adquirido en los últimos años el mundo cultural, decidían irse a vivir a ella para conocer de primera mano lo que allí ocurría. Como ocurrió en el caso de Patricia Gadea y Juan Ugalde y una década antes con Dionisio Cañas.

3. La diferencia entre Nueva York y Madrid era demasiado grande a nivel cultural. Por este motivo los componentes del grupo Estrujenbank, disconformes con la situación española, decidieron aunar sus fuerzas formando un colectivo que luchase contra la actitud mercantilista del arte, un grupo que pudiese suponer una alternativa a todas las influencias extranjeras mostradas en España.

4. Estrujenbank gracias a los esfuerzos de Patricia Gadea y de Juan Ugalde abrieron una sala de arte independiente en un barrio obrero. Sus objetivos fueron por un lado crear un espacio en el que jóvenes artistas pudiesen exponer sus obras con total

23 AA.VV. Doméstico, cuatro ediciones en un libro/ Four editions in one book, Asociación cultural Doméstico, Madrid, 2005, p. 184. 
libertad, sin condicionantes, en exposiciones colectivas y por otro intentaban acercar el ambiente cultural a un barrio obrero con poca o nula tradición artística, puesto que la sala estaba ubicada en el barrio madrileño de Legazpi.

5. Estrujenbank tuvo siempre un especial interés en realizar una obra comprensible por todo el mundo, intentando evitar el elitismo que rodeaba habitualmente al mundo del arte contemporáneo. Por ese motivo todo lo popular fue observado, analizado y copiado posteriormente en la realización de sus obras.

6. Estrujenbank fue un grupo muy activo que contempló como actividades complementarias a su trabajo en el taller y al funcionamiento de su sala, la edición de libros y revistas, la realización de perfomances y el comisariado de exposiciones.

7. Aunque en la época no tuvieron una gran repercusión, fue la suya una iniciativa muy arriesgada, creando un espacio independiente en su época en Madrid y generando un lugar de reunión para muchos jóvenes creadores a los que influyó ese espíritu Estrujenbank, con los que compartieron preocupaciones e inquietudes. 